\title{
Ecology of Moscow urban agglomeration: problems and the ways of solving
}

\author{
Sergey Mezentzev* \\ Moscow State University of Civil Engineering, Yaroslavskoe shosse, 26, Moscow, 129337, Russia
}

\begin{abstract}
The present paper approaches the current ecological issues of Moscow urban agglomeration, including Moscow, the capital city of Russia, and Moscow region as well as the ways in which these issues could be solved. In the course of research, there have been used system and complex approaches, the methods of analysis, synthesis, abstraction, generalization, mental simulation, the methods of observation, comparison, statistical methods, and visualization. It was noted that the significant concentration of population in Moscow urban agglomeration leads to the population overflow and acute ecological problems on the given territory. Currently, ecological system of Moscow urban agglomeration represents the collective of interrelated and interconnected natural, anthropogenic and techno genic components. Techno genic and anthropogenic causes of environmental pollution, such as urban planning, industrial enterprises, power plants, transport, communication systems, domestic rubbish and wastes, have been studied in details. Also, there was given comparison of ecological situation of Moscow urban agglomeration, from one side, and the Netherlands, the Tula and Kursk regions of Russia, from the other side. Then, the transition to the search of new way of solving of ecological problems is done. As the most effective methods of ecological problem solving and reducing anthropogenic impact on environment, there were proposed: the lowering of migration flows into Moscow urban agglomeration, the use of renewable energy sources, non-waste technologies, construction of rubbish recycling plants and treatment facilities, liquidation of unauthorized disposal fields, substitution of the combustion engine transport by the transport with electrical engines.
\end{abstract}

\section{Introduction}

Despite the growing scientific literacy and technological capitalization, the impact of humankind on the environment remains of unplanned, uncontrolled nature, while ecological problems have become global issues in the XX century and have a tendency to aggravate. Along with that, here comes the understanding of new European paradigm of eutechnics, i.e. mastery of nature and its sources, according to which the nature is regarded as an inexaustible reservoir of resources designated for technical activity of humankind. Such a paradigm

\footnotetext{
* Corresponding author: mesenzew@mgsu.ru
} 
should be replaced by the meaningful adaptation of the community to the credible environmental resources.

Notwithstanding that, ecological issues are of global type, they differ by countries and regions. One of the spectacular examples is Moscow urban agglomeration comprising the city of Moscow and Moscow region at the large scale (Fig. 1) [1]. By its territory, population size and density Moscow urban agglomeration is comparable with the Netherlands (fig. 2). At the same time, by the GDP volume Moscow urban agglomeration is significantly inferior to the Netherlands. According to the data of the International Monetary Fund, the GDP of the Netherlands accounted for $\$ 907$ bln in 2019, when of Moscow urban agglomeration is close to $\$ 425$ bln correspondingly (about $25 \%$ of the total GDP of the Russian Federation, equal to $\$ 1702$ bln) [2].

Fig. 1. Map of Moscow urban agglomeration

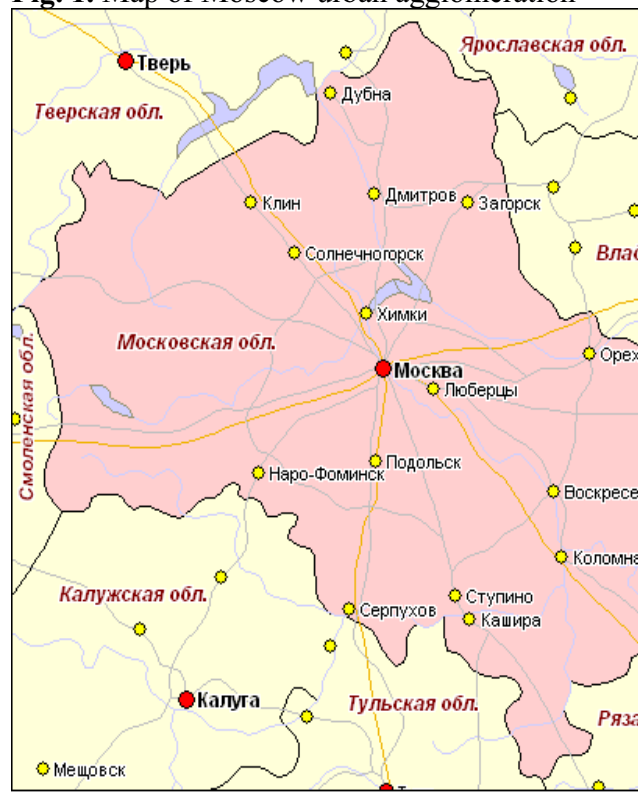

Area: 46.99 square km. Population: $20.35 \mathrm{mln}$ people (as for 01.01.2021). Population density: 433 people per 1 square $\mathrm{km}$.
Fig. 2. Map of the Netherlands



Area: 41.53 square $\mathrm{km}$. Population: $17.176 \mathrm{mln}$ people (as for the beginning of 2021). Population density: 414 people per 1 square $\mathrm{km}$.

The first factor influencing immensely on environmental setting is techno genic manmade environment, i.e. industrial enterprises and transport. The second one is anthropogenic activity of human being. The third one, surprisingly, natural habitat and geographical location. It is clearly seen at the example of the Netherlands. The Netherlands, as opposed to Moscow urban agglomeration, are located at the seaside and exposed to strong offshore winds bringing in relatively clean air. Located inland, Moscow urban agglomeration experiences the additional environmental deterioration, specifically pronounced in the period of highpressure areas. The aggravated ecological situation damages not only the environment but also the people residing on the given territory. Due to this, the problem of intensifying environmental protection measures, transition from the things in existence to the dues is of 
paramount importance [3]. Moreover, the measures undertaken in particular countries, including the Netherlands, bring beneficial effects [4].

Due to continuous deterioration of ecological situation in Moscow urban agglomeration, the relevance of the present research is evident, and its purpose is to determine the key ecological problems and the ways of their possible solution.

\section{Materials and methods}

In order to achieve the set goal, both theoretical and empirical research methods have been applied.

The main scientific approaches are system approach and complex investigation. This is preconditioned by the fact that current ecological situation in the world and in Moscow urban agglomeration in particular is the result of disregard of nature and society uniformity, dereliction of the laws of their interdependency and interconditionality.

Application of system approach allowed considering ecological problems and finding the ways of their solution in the light of wholeness of interconnected elements, the summary of interacting objects as well as their essence and relationship. For this purpose, the materials of social ecology, the sub discipline studying interaction of human community and nature, have been used. In the framework of social ecology, Commoner B., Girusov E. and other scientists have formulated important ecological laws and principles. Thus, for instance, Barry Commoner has concluded that: 1) everything is connected to everything else; 2) everything must go somewhere; 3 ) nature knows best; 4) there is no such thing as a free lunch [5]. The system of nature is integral whole. Everything extracted from the nature by human efforts must be restituted. The debt security payments cannot be avoided, they can only by postponed.

The following ecological principles are derived from the above: 1) the principle of optimal concordance of society and human habitat; 2) the principle of necessity of maintaining natural equilibrium; 3) the principle of compensation in compliance with the measure of natural resources exaction; 4) the principle of ecological cleanness of human activity; 5) the principle of complexity and ecological feasibility of taken decisions [6]. It was N.Ph. Reimers who has formulated ecological laws, principles and regulations to the fullest extent possible (about 250) [7]. Along with the mentioned materials, the author has carried out thorough investigation of the latest publications that had reflected ecological issues of Moscow urban agglomeration [8, 9, 10, 11].

The complex investigation has been carried out by means of the system of methods (analysis, abstraction and others). Application of these methods enabled to reveal and cover the maximum possible number of significant parameters for the ecological situation in Moscow urban agglomeration under investigation.

Having applied the method of analysis, the multitude of ecological problems in Moscow urban agglomeration was found. Then, the results of analysis have been united into the whole by synthesis.

Having applied the abstraction method, the most vital ecological problems were singled out from the multitude and, basing on the theme of the present research, marginal problems were neglected. Generalization method enabled to determine essential features of ecological problems and identify the ways of their solution.

In the course of the research, mental simulation of the proper state of Moscow urban agglomeration was implemented with the purpose to find the ways of ecological problems solving and to obtain sustainable environment. 
Evaluation of ecological situation in Moscow urban agglomeration was done by the observation method, while by the comparison method, the similarities and differences in ecological situations of Moscow urban agglomeration, the Netherlands, Tula and Kursk regions were outlined.

Statistical methods allowed operating statistical data. Some aspects of ecological problems and the possible ways of their solution were starkly illustrated by visualization method.

\section{Results and discussion}

Moscow is the largest metropolis in Russia, whereas Moscow region occupies the second position after Moscow by the number of inhabitants. The dense population concentration in Moscow urban agglomeration leads to overpopulating this territory, aggravating ecological problems and even 'shrinkage' of Russia to the borders of Moscovia [12]. As opposed to the Netherlands, with relatively even distribution of population across the territory, Moscow dominates in Moscow urban agglomeration by the number of inhabitants.

If the growth of population size per se in Moscow urban agglomeration deteriorates ecological situation in the region due to extreme impact on nature, anthropogenic and techno genic activity of humans significantly increases environmental pollution. Moreover, this occurs at such extent that the nature itself cannot cope with the current volume of contaminants polluting the environment and recover without the human involvement.

Ecological system of Moscow urban agglomeration represents the summary of natural, anthropogenic and techno genic components (fig. 3). Human being occupies the central position in this system, whereas human activity leads to ecological problems, and the future development of Moscow urban agglomeration depends on human being as well.

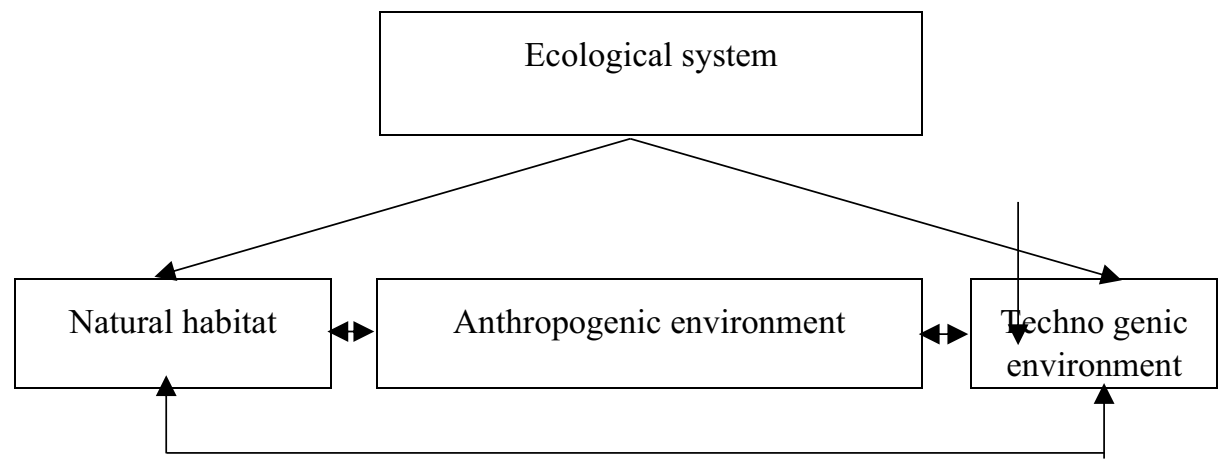

Fig. 3. Ecological system of Moscow urban agglomeration

In Moscow urban agglomeration, natural habitat comprising geographical location, landscape, atmosphere, geological framework, forests, water resources and bioresources represents the space transformed by humans in their sole discretion. Unfortunately not much left from its natural state, apart from geographical location and geological framework. Landscape is being changed, atmosphere and water resources are being polluted, forests area is shrinking, bioresources are evolving and adapting to the surrounding transformation.

Anthropogenic environment includes two constituent parts: natural and manmade. The former comprises organic wastes of human activity. The latter includes transformed natural habitat, i.e. natural reserves, recreational areas and other natural anthropogenic objects as well as household waste and rubbish. Annually, the residents of Moscow urban agglomeration produce few millions tons of wastes, therefore their disposal and utilization is 
extremely acute problem [13]. The deposits of solid municipal wastes in Moscow region are overfilled. It is evident that plastic, polyethylene, glass and some others are the most harmful materials for environment.

However, techno genic environment, which includes urban planning, industrial enterprises, power plants, transport and communication systems, causes the maximum environmental damage. Dynamic urban planning in Moscow agglomeration demands new territories for further development. As there are almost no available sites left for construction operation, trees are felled, floodplains are dewatered, agricultural lands change their designation, etc. Modern urban construction uses such building materials that cannot be recycled by nature, for example, concrete. This is not like typical country houses and cottages built of timber. Wooden houses successfully blend with the natural environment and timber could be further utilized. Industrial enterprises, various structures, motorways, building and houses erected of stone, reinforced concrete, asphalt and glass are built to stay for decades or even centuries. The number of such objects on the territory of Moscow urban agglomeration is ever increasing. When these objects are pulled down and demolished, the vast volume of industrial wastes and rubbish is formed. These wastes require recycling and utilization to prevent environmental pollution [14].

Industrial enterprises and power plants produce industrial wastes and pollute, primarily, air, water and soil. Burning of coal, natural gas, petrochemical products leads to emission of the enormous amount of carbon dioxide into the atmosphere, which then contaminates water and soil. Accidents occasionally happening at industrial enterprises and other technical objects deteriorate ecological situation at a greater extent. Transport equipped with combustion engines contribute greatly to the environmental pollution [15]. In the internal combustion engine, blended fuel burns directly in the working chamber (inside) of the engine and then belched out. This is one of the main sources of carbon dioxide emission $\left(\mathrm{CO}_{2}\right)$. The problem lies not only in the fact that the average family residing in Moscow urban agglomeration possesses 2-3 vehicles (according to the statistical data, currently 400 vehicles are registered per 1000 residents of the agglomeration). Moscow is also a large transport hub, with thousands of heavy good vehicles moving along the streets and roads and staying in traffic jams daily.

Communication system, which comprises power transmission lines, pipelines, roads, streets, is regarded as another significant factor intervening the nature and contributing to environmental pollution [16, 17]. The highest spreading and density of power transmission lines, pipelines, roads and streets in Russia is registered exactly in Moscow urban agglomeration. They have noticeable impact on the natural landscape. In order to construct and maintain power transmission lines, roads and streets, wide branch trails in forests and woodland belts are cleared. This sometimes leads to river diversion, water drainage, the boundaries of lands, and destroys the natural habitat of wild animals and migrating birds. Treatment of motorways and streets with chemicals and salts in winter period is considered an additional adverse event for ecology.

There exist some other problems in Moscow urban agglomeration such as noise pollution caused by construction operations, automobile transport, trams, underground trains, auditory advertising, motorways, etc. If compared with the above-mentioned factors, noise pollution is not that damaging for the environment and humans, as it does not influence harmfully on ecological situation.

Comparing ecological state of environment in Moscow urban agglomeration, the Netherlands, Tula and Kursk regions, the following phenomena are observed. Large industrial cities have a greatest impact on environment [18]. If towns and settlements are not 
large by the number of residents and scattered across the vast territory, the negative influence on nature is minimized. In this case, nature can cope successfully with release of wastes and contaminants. Agriculture also plays an important role in environmental pollution though less noticeable than industry and transport. It is rather prominent in Tula and Kursk regions, for example. The level of development is of paramount importance in this scenario. Thus, higher level of economic and technological development of the Netherlands allows Dutch citizens to solve ecological problems more successfully than in Moscow urban agglomeration [19].

What kinds of solution of ecological problems are proposed in Moscow urban agglomeration? What innovative methods could be applied for their solving?

1. The rapid population growth in Moscow urban agglomeration eventually leads to significant deterioration of ecological situation. It is necessary to undertake measures for restricting migration flows from other regions in order to lower anthropogenic influence on environment. This could be done by development of other constituent entities of the Russian Federation, in particular of those with vast undeveloped and open districts. Urban projects should be reoriented towards Siberia and Far East that are presently in decline [20].

2. Shifting of industrial enterprises outside Moscow and Moscow region has not produced the desired effect. Nevertheless, the amount of harmful emission remains great. The possible solution of environmental pollution by industrial emissions and wastes could be found in renewable energy sources, non-waste technologies, and construction of treatment facilities. Dutch experience when the share of electric power produced from renewable sources is approaching to $20 \%$, and the whole network of waste-recycling plants and other enterprises designated for environmental protection is constructed, could serve as a benchmark. All these processes are at their first set-out in Moscow urban agglomeration. During the last few years, waste is collected more efficiently (fig. 4), incinerating and wasterecycling plants are erected in Moscow region (fig. 5) [21, 22, 23]. The attempts to shift the construction of solid municipal waste deposits into the neighboring regions, in particular, Arkhangelsk region, were not crowned with success. Due to the protests of local residents, the construction of waste deposit in Shies was halted in 2020 [24].

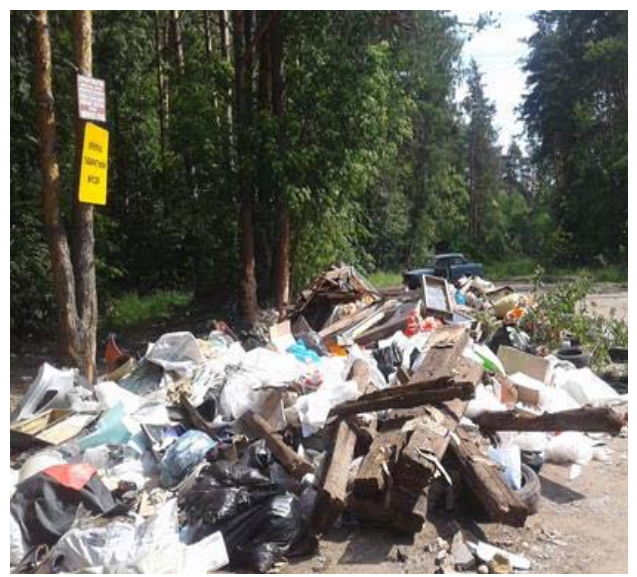

Fig. 4. Illegal waste and rubbish deposit

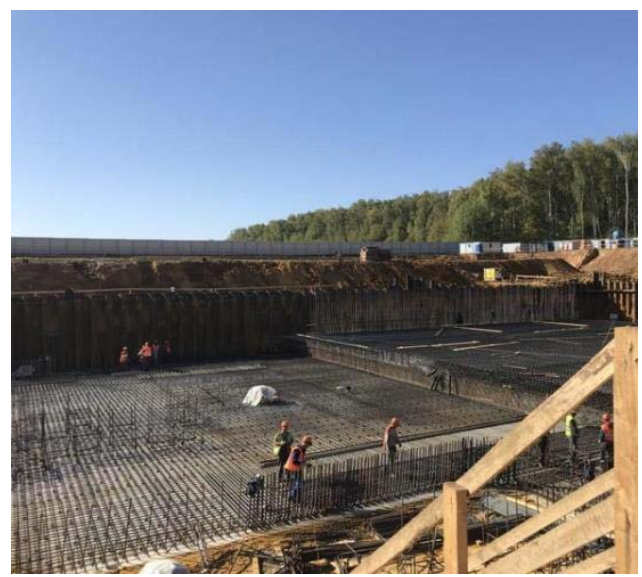

Fig. 5. Construction of waste-recycling plant 
3. In order to improve ecological situation in Moscow urban agglomeration, it is vital to lower transport-induced pollution. The measures undertaken for construction of new motorways, junctions, daytime heavy-goods vehicle ban in Moscow, shift of public transport to higher environmental class (EURO 5 and higher), development of cycle tracks have not produced a meaningful effect. Only transition to electric transport could be seen as cardinal methods of environmental problem solution [25]. However, Moscow urban agglomeration is at the very outset in this sphere. In 2018, the first electric buses appeared on the streets of Moscow, designated for substitution of all public transport with internal combustion engines (fig. 6). However, electric buses are equipped with additional diesel units for heating passengers' compartment in wintertime. There comes the time of heavy-duty and light-duty electric cars that are gaining popularity all over the world (fig. 7,8).

Fig. 7. Electric bus KamAZ 6282

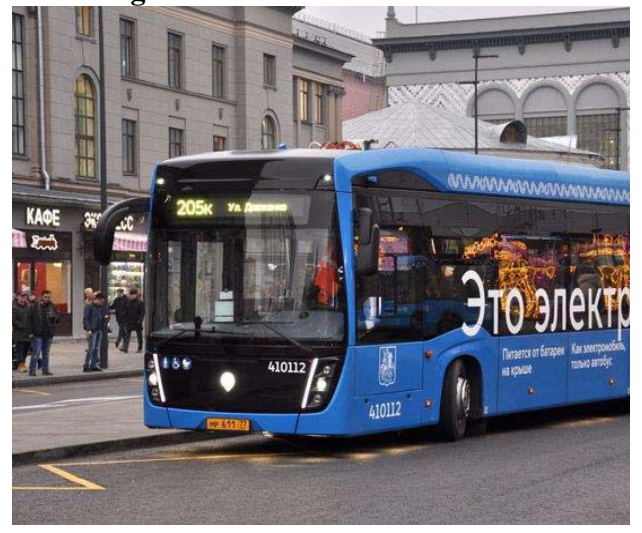

Fig. 8. Electric car Tesla Model S

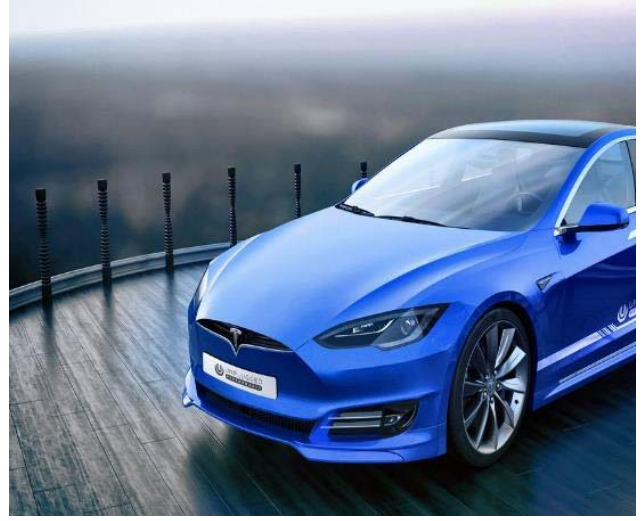

\section{Conclusions}

Combination of natural elements (geographical location, natural landscape, air masses flow, etc.), anthropogenic (population growth, urbanization, municipal wastes, etc.) and techno genic factors (industry, transport equipped with internal combustion engines, communication system, etc.) has an impact on ecological situation of Moscow urban agglomeration. Moscow urban agglomeration is facing the issues typical for any metropolitan district in the world, caused by overpopulation and environmental pollution. Thus, the experience accumulated in foreign countries could be successfully applied for solving these problems.

Industrial and domestic wastes, deposits, discharge of power plants and other enterprises, automobile emissions, sewage, which cannot be treated by obsolete methods and technologies, - the list of environmental pollution sources is far from its complete. Partial solution of these issues will lead to purification of air, water and soil that are currently in critical state in Moscow urban agglomeration. Nowadays, this task is technically and technologically feasible and could be achieved by directing urban planning policy towards other Russian regions, the use of renewable energy sources and non-waste technologies, construction of waste-recycling plants and sewage treatment facilities, as well as transition to electric transport. All these measures should be undertaken to keep air, forests, parks, lakes and rivers clean for future generations. 


\section{References}

1. V.Glushkova, Moscow agglomeration, Moscow, Great Russian encyclopedia, 499 (1997)

2. The list of countries by GDP, access mode:

https://ru.wikipedia.org/wiki/\%D0\%A1\%D0\%BF\%D0\%B8\%D1\%81\%D0\%BE\%D0\%

BA_\%D1\%81\%D1\%82\%D1\%80\%D0\%B0\%D0\%BD_\%D0\%BF\%D0\%BE_\%D0\%92

$\% \mathrm{D} 0 \% 92 \% \mathrm{D} 0 \% 9 \mathrm{~F} \_$( $\%$ D0\%BD $\% \mathrm{D} 0 \% \mathrm{BE} \% \mathrm{D} 0 \% \mathrm{BC} \% \mathrm{D} 0 \% \mathrm{~B} 8 \% \mathrm{D} 0 \% \mathrm{BD} \% \mathrm{D} 0 \% \mathrm{~B} 0 \% \mathrm{D}$ $0 \% \mathrm{BB})(2021)$

3. S. Mezentsev, Modern urban planning: dues and existing, ideals and reality, J. Vestnik MGSU, 4, 389 (2010)

4. Environment Status and prospects - 2020. Summary, European Environment Agency. Copenhagen, 14 (2019)

5. B. Commoner. The Closing Circle: Nature, Man, and Technology, New York: Knopf Press, 339 (1971)

6. E.Girusov, The fundamentals of social ecology, Moscow, Algorithm, 496 (2002)

7. N. Raymers, Ecology (theories, laws, rules, principles and hypothesis), Moscow, J. Rossiya Molodaya, 367 (1994)

8. R. Mamin, G. Orekhov, A.Bayrasheva, Urbanization and ecological safety of the territories of New Moscow, Moscow, ASV, 112 (2015)

9. V.Chernyshov, V.Zykov, About the perspective methods of evaluation of ecological state of the region, Moscow, RUDN, 174 (2014)

10. A. Yablokov, Unsolved ecological problems of Moscow and Moscow Region, Moscow, Meida-Press, 400 (2012)

11. About environmental pollution of the territory of Moscow and Moscow region 20082021 , access mode: http://www.meteorf.ru/product/infomaterials/100/?year=2021\&ID=100 (2021)

12. S. Mezentsev, Problems of spatial planning, zoning and urban development in modern Russia, Innovative Technologies in Environmental Science and Education (ITESE2019) E3S (2019)

13. M. Bodnaruk, S.Popov, O.Kozlov, The modern problems of recycling of municipal wastes in nature management, J. Mining information and analytic bulletin, 4 (10), 3 (2012)

14. I. Yazhdev, Ecological rehabilitation of polluted industrial and urban territories, Moscow, ASV, 279 (2012)

15. D.Kolyshkina, D.Aydov, L.Kushchenko, Negative impact of automobile transport on ecology, J. Innovative Science, 2, 36 (2019)

16. S.Govorushko, Erecting and maintenance of pipelines: impact on environment, J. Ecology of industrial production, 3, 23 (2011)

17. Yu. Yanchu, N.Teniryadko, Automobile roads and environment, Proceedings of AllRussian conference with international participation, Moscow, Pero, 385 (2019)

18. The state of atmosphere pollution in cities on the territory of Russia, Saint Petersburg, GGO Rosgidromet, 287 (2015)

19. I. Andreev, Below the sea level. Managing natural risks in the Netherlands, J. Engineering safety, 6, 74 (2015)

20. O.Goranova, Sustainable development of Moscow urban agglomeration, Bulletin of the Moscow Government University, 4, 10 (2017)

21. A. Kolb, Illegal wastes deposits: the expertise of federal cities, J. Reference guide of ecologist, 1, 34 (2019) 
22. From the beginning of the year in Voskresensky district there were liquidated 760 cubic meters of wastes, access mode: https://gatn.mosreg.ru/sobytiya/novosti_ministerstva/2007-2017-12-29-32-s-nachala-goda-v-voskresenskom-rayone-likvidirovan (2017)

23. The second stage of construction of garbage incineration unit has launched in Moscow region, access mode: https://sdelanounas.ru/blogs/112287/ (2021)

24. Ecoactivists announced the cessation of protests against construction of waste deposit on Shiese, access mode: https://takiedela.ru/news/2021/01/09/kampaniya-na-shiesezakonchilas/ (2021)

25. L. Grigoryev, To future without petrol, Automobile roads, 1, 71 (2019) 